Review

\title{
Yellow submarine of the Wnt/Frizzled signaling: Submerging from the $G$ protein harbor to the targets ${ }^{\text {is }}$
}

\author{
Alexey Koval $^{\mathrm{a}, \mathrm{b}}$, Vladimir Purvanov ${ }^{\mathrm{b}}$, Diane Egger-Adam ${ }^{\mathrm{b}}$, Vladimir L. Katanaev ${ }^{\mathrm{a}, \mathrm{b}, \mathrm{c}, *}$ \\ a Département of Pharmacology and Toxicology, University of Lausanne, Rue du Bugnon 27, CH-1005 Lausanne, Switzerland \\ ${ }^{\mathrm{b}}$ University of Konstanz, Universitätsstrasse 10, 78457 Konstanz, Germany \\ ${ }^{\mathrm{c}}$ Institute of Protein Research, Russian Academy of Sciences, Institutskaya St. 4, 142290 Pushchino, Russian Federation
}

\section{A R T I C L E I N F O}

\section{Article history:}

Received 30 April 2011

Accepted 2 June 2011

Available online 13 June 2011

\section{Keywords:}

Wnt

Frizzled

GPCR

Heterotrimeric $G$ protein

Rab5

\begin{abstract}
A B S T R A C T
The Wnt/Frizzled signaling pathway plays multiple functions in animal development and, when deregulated, in human disease. The G-protein coupled receptor (GPCR) Frizzled and its cognate heterotrimeric $\mathrm{Gi} / \mathrm{o}$ proteins initiate the intracellular signaling cascades resulting in cell fate determination and polarization. In this review, we summarize the knowledge on the ligand recognition, biochemistry, modifications and interacting partners of the Frizzled proteins viewed as GPCRs. We also discuss the effectors of the heterotrimeric Go protein in Frizzled signaling. One group of these effectors is represented by small GTPases of the Rab family, which amplify the initial Wnt/Frizzled signal. Another effector is the negative regulator of Wnt signaling Axin, which becomes deactivated in response to Go action. The discovery of the GPCR properties of Frizzled receptors not only provides mechanistic understanding to their signaling pathways, but also paves new avenues for the drug discovery efforts.
\end{abstract} (c) 2011 Elsevier Inc. All rights reserved.

\section{Contents}

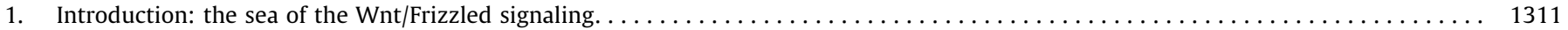

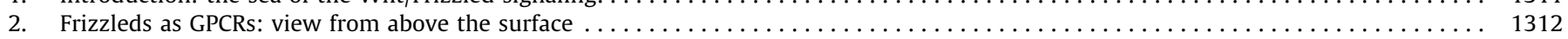

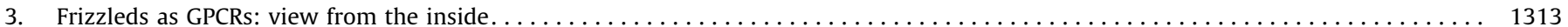

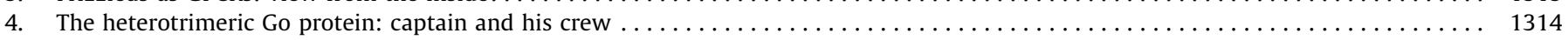

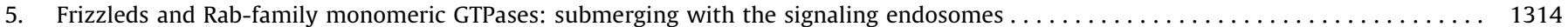

6. Axin as Neptune of the deep-water Wnt/Frizzled signaling: the many ways to appease the evil god . . . . . . . . . . . . 1315

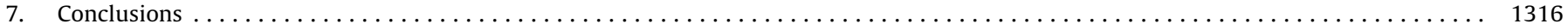

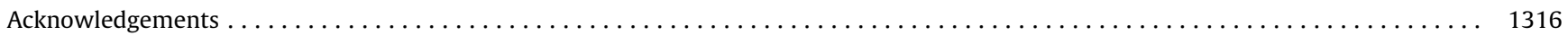

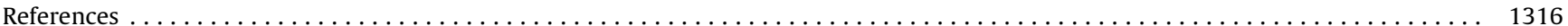

\section{Introduction: the sea of the Wnt/Frizzled signaling}

Wnt signaling plays instructive roles in animal development, conserved from sponges to human beings, to activate the $\beta$-catenindependent transcriptional regulation of cell fate specification [1]. In the adult, this pathway is mostly silent. However, both improper overactivation and underactivation of this pathway can lead to

\footnotetext{
The "Yellow Submarine" theme refers to the song of the same name from The Beatles.

* Corresponding author at: Department of Pharmacology and Toxicology, University of Lausanne, Rue du Bugnon 27, CH-1005 Lausanne, Switzerland. Tel.: +41216925459.

E-mail address: Vladimir.Katanaev@unil.ch (V.L. Katanaev).
}

diseases. Insufficient Wnt pathway activity underlies defects in tissue regeneration and the decreased proliferative potential of various stem cells [2,3]; it may also lead to certain neurodegenerative disorders [4]. On the other hand, misactivation of this signaling, e.g. through overproduction of the Wnt ligands or mutational activation of the downstream components of the pathway, promotes carcinogenesis, especially in the colon and breast [5,6]. In addition to this "canonical" $\beta$-catenin-dependent pathway, Wnt signaling also controls establishment of epithelial planar cell polarity (PCP). PCP is characterized by uniform polarization of the epithelial tissue within the plane of the epithelium, perpendicular to the typical apico-basal polarization of epithelial cells [7].

Frizzled $(\mathrm{Fz})$ proteins have been identified as the receptors for the Wnt lipoglycoprotein ligands [8]. The first Fz cloned was that of 
Drosophila, and the lab of Paul Adler disclosed the primary structure of this protein $[9,10]$ as a 7 -transmembrane helix (7-TM) receptor. This discovery happened 15 years after the pioneering works describing the existence of this transmembrane topology [11] and a decade since the prediction methods for this specific arrangement had emerged $[12,13]$. Reliability and simplicity of such methods based on the hydropathicity profile over the protein length allowed the 7-TM topology of the Fz protein to be no matter for any controversy. In contrast, the idea that 7-TM receptors may have the general feature of coupling to heterotrimeric G-proteins had been formulated only a few years earlier [14], but soon became widely accepted, and the words "7-TM receptors" and " $G$ proteincoupled receptors (GPCR)" became essentially synonymous.

Heterotrimeric $G$ proteins represent the immediate cytoplasmic transducers of GPCRs [15-17]. Upon binding of the agonist the receptor undergoes conformational changes, which enhance its GEF (guanine nucleotide exchange factor) activity towards the $\alpha$-subunit of the heterotrimeric G protein. As a result, the $\alpha$-subunit exchanges its GDP for GTP and dissociates from the $\beta \gamma$-heterodimer. G $\alpha$-GTP is then capable of interacting with downstream effectors until its intrinsic GTPase activity converts GTP back into GDP, leading to reassociation of the heterotrimeric complex, which brings the system to the "point zero". GPCRs interact with one or several types of G proteins, the specificity being determined by their $\alpha$-subunits. Unlike more promiscuous $\beta \gamma$ dimers [18], $\alpha$-subunits are capable of signaling to specific effectors; the human genome contains 16 genes for different $\alpha$ -

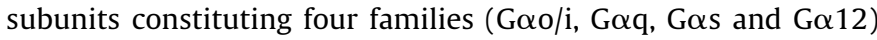
[16]. Typically, any given cell expresses multiple types of heterotrimeric G-proteins [19].

Despite the growing body of evidence of GPCR coupling to heterotrimeric G-proteins, the data for the involvement of such transducers in Wnt/Fz signaling was missing for many years. Thus the $G$ proteins were omitted from the emerging pathway architecture, being overshadowed by other major components of the cascade $[8,20-22]$. The first evidence which returned the missing $G$ protein link in the chain of the Fz signal transduction was the role of pertussis toxin-sensitive $G$ proteins obtained for the Fz-dependent non-canonical $\mathrm{Ca}^{2+}$-pathway in zebrafish [23]. Later the Go-protein was found to be a transducer in both canonical and PCP pathways in Drosophila [24-26], and roles for its orthologues along with other members of the heterotrimeric GTPase superfamily in Xenopus $[27,28]$ and mammalian models [28-31] of $\beta$ catenin stabilization as well as cell polarization [32] were established. Although these findings suggested that Fz proteins were activators of G-proteins, only recently the final biochemical proof of the ability of Fz receptors to bind heterotrimeric Gproteins and activate the nucleotide exchange on them upon engaging the Wnt ligands has been provided [33-35] - the final demonstration that these receptors are bona fide GPCRs [36-38]. Thus when all the i's are dotted and the t's are crossed, it is time to use the vast experience obtained in the field of GPCR functioning and pharmacology to bring us new concepts and insights into the work of the Fz pathway and ultimately to facilitate development of the drugs targeting it. This will be the focus of our review, followed by discussion of which effectors $G$ proteins talk to upon transduction of the Wnt/Fz pathway.

\section{Frizzleds as GPCRs: view from above the surface}

GPCRs bear certain motifs in the extracellular and intracellular sequences, recognizable for their interactions with ligands and effectors. Fz receptors are no exception to this rule [39], and we proceed with description of the current knowledge of their features. On the extracellular side, Fz proteins carry a well-defined $\mathrm{N}$-terminal cysteine-rich domain (CRD). The CRD contains ten cysteines conserved among the $\mathrm{Fz}$ receptor family [40]. This domain has been proposed as the main ligand-binding region of the receptor, and indeed a physical interaction of purified CRD with Wnt ligands has been demonstrated [41,42]. Additional proof for the role of CRD in Wnt binding comes from the fact that the socalled secreted Fz-related proteins (SFRPs), consisting essentially of just CRDs, serve as natural antagonists of Wnt signaling by competing with $\mathrm{Fz}$ for the interaction with Wnt ligands [43]. However, CRD is also present in the Smoothened receptor [44], which functions as a constitutive GPCR in the Hedgehog signaling pathway and has no influence on Wnt signaling. Additionally, experiments in Drosophila have demonstrated that a CRD-less Fz can efficiently rescue $\mathrm{Fz}$ loss-of-function alleles [45], suggesting that CRD is not the sole Wnt-binding region of the receptors. It is conceivable that a two-step ligand binding mechanism, known for some other GPCRs [46], also applies to Fzs, so that the Wnt-binding CRD serves to increase the local concentration of the ligand in the receptor's vicinity, while binding to the second site is required to trigger structural rearrangements in the GPCR and activate signal transduction.

Given the likely existence of several Wnt interaction regions in Fz receptors, the available information on the affinity of various Fz' CRDs for Wnt ligands [42] may not have a straightforward relevance for the physiological interactions between Wnts (19 in humans, 7 in Drosophila) and Fzs (ten in humans, four in flies). A systematic functional analysis of the Wnt-Fz interaction pairs is missing and requires an easy read-out system, measuring the most immediate events following the ligand-receptor interaction, rather than the final transcriptional response which is often affected by complicated feed-back regulations and depends on the exact composition of downstream elements of the cellular signaling machinery $[47,48]$. Until recently such read-outs were unavailable. Our experiments biochemically probing the GPCR activity of Fzs close this gap [33,34,49,50]. Indeed, the ability of a GPCR to catalyze guanine nucleotide substitution on the $\mathrm{G} \alpha-$ subunit is the most immediate consequence of the conformational change induced by ligand recognition, and can be easily measured. Using this assay, we have begun the systematic analysis of the Wnt-Fz coupling $[33,34]$ and identified that human Fz1 is efficiently activated by Wnt3a and Wnt5a, Fz6 - by Wnt7a, Fz7 by Wnt5a, and Fz10 - by Wnt3a. This set-up is also primed to be used in a high-throughput screening of small molecule antagonists of the Wnt-Fz interactions [50], the long-desired endeavor which might yield novel anti-cancer lead compounds [6].

Which factors apart from the intrinsic properties of the Fz GPCR may influence the specificity of the ligand binding? The mode of ligand interaction with a GPCR can be influenced by co-receptors such as LRP5/6 for the canonical Fz signaling and Ror1/2 for the PCP signaling [51]. LRP5/6 are single-pass transmembrane proteins participating in a ternary complex with Wnt and Fz [52]. Recent evidence suggests that LRP5/6 may act as general GPCR accessory proteins, enabling non-Fz GPCRs to signal through the $\beta$-catenin pathway [53,54]. In this regard, LRP5/6 and Ror $1 / 2$ may be viewed as RAMPs (receptor-activity-modifying proteins): single-transmembrane accessory proteins regulating GPCRs [55].

Another potential level of complexity brought by LRP5/6 is their expected ability, as members of the lipoprotein receptor proteins, to interact with lipoprotein particles [56]. This becomes highly relevant in the context of Wnt signaling, as multiple forms of packaging of natural Wnt ligands have been proposed, including incorporation of the ligands into lipoprotein particles [57-59]. Wnts, being lipid-modified glycoproteins, easily bind to the outer cell membrane and extracellular matrix and are thus poorly diffusive as monomers [60], yet can migrate over long distances in vivo. It has been proposed that different ways to package Wnts serve to activate different groups of cells in the natural 
environment, depending on the location of these cells regarding the source of production of the Wnt morphogens $[61,62]$. It is conceivable that different subtypes of the intracellular signaling pathways are activated by different forms of Wnts, and circumstantial evidence exists in favor of this idea [63-65]. LRP5/6, capable of interacting with lipoprotein particles, might play different roles in the recognition of the different forms of Wnt ligands and initiation of different subtypes of signaling.

Ligand recognition by $\mathrm{Fz}$ receptors may also be affected by $\mathrm{Fz}$ homo- and hetero-dimerization - a typical feature in GPCR physiology [66]. The very first evidence for Fz dimerization was provided by the structure of the mouse Fz8 CRD [67], which was crystallized as symmetrical homodimers. Subsequent investigations with full-length proteins confirmed the role of the extracellular domain in receptor dimerization and oligomerization [68]. However, human Fz4 was shown to dimerize even in the absence of the CRD through the 7-TM region of the receptor [69], similarly to some other GPCRs of the A and B class [70]. Nevertheless both studies [68,69] found di- or oligomerization essential for the proper receptor trafficking and signal transduction. Since Fz dimerization was sensitive to reducing agents $[68,69]$, extracellular intra-molecule disulfide bridges are likely to play a role in the dimer formation, as has been proposed for some other GPCRs [71]. Heterodimerization of Fz proteins has also been proposed [69], which brings along further potential flexibility in ligand recognition and transduction. Furthermore, it is conceivable that Fz heterodimerization with other, non-Fz GPCRs may exist, which provides a possible explanation for the involvement of non-Gi/o heterotrimeric $G$ proteins in Wnt pathways $[28,30]$ (see below).

\section{Frizzleds as GPCRs: view from the inside}

On the inner side of the plasma membrane the C-terminal part and the intracellular loops of $\mathrm{Fz}$ receptors mediate interactions with $G$ proteins and other regulatory components. Fzs possess rather short C-termini, with the conserved KTXXXW (X = any amino acid) motif [72] which binds the PDZ domain of the scaffolding protein Disheveled (Dvl) [73]. Dvl is one of the major transducers of $\mathrm{Fz}$ in both the canonical and PCP branches of $\mathrm{Fz}$ signaling [74,75]. Through its DIX domain, Dvl interacts with Axin - the negative regulator of the canonical Fz pathway [76,77]. This interaction contributes to the disassembly of the Axin-based $\beta$ catenin destruction complex [78,79]. In the PCP branch, Dvl accumulates together with $\mathrm{Fz}$ in endosomes, which are actively transported in the posterior direction and released back to the plasma membrane at the apical posterior tip of the epithelia $[80,81]$ - phenomenon required for the amplification of the initial Fz-activating signal and establishment of the uniform planar polarization of the tissue. In addition to Dvl, other PDZ-containing proteins (e.g. Kermit/GIPC [82], PSD95 [83], GOPC [84]) have also been shown to interact with Fz. These binding partners are involved in the regulation of the Wnt pathway via modulation of the $G$ protein activity (such as recruiting RGS proteins in case of Kermit/GIPC $[85,86]$ ) or mediating proper receptor distribution and trafficking [87].

A well-described way of GPCR regulation is their inactivation through sequential phosphorylation by GRKs ( $G$ protein-coupled receptor kinases) or other kinases, followed by interaction with $\beta$ arrestin which prevents $G$ protein binding and triggers GPCR internalization [88]. So far, there is no evidence for $\beta$-arrestins or GRKs to directly interact with $\mathrm{Fz}$ proteins, although both are involved in the Wnt pathway in rather unusual ways. Specifically, it was found that the $\beta$-arrestin's role in Fz internalization was mediated by the hyperphosphorylated form of Dvl [89-91], while GRKs participated in this pathway by phosphorylating LRP6 [92] which was also important for the receptor-ligand complex internalization. Fzs themselves also have multiple putative phosphorylation sites [39], and direct phosphorylation of several Fzs by different kinases has been demonstrated [93,94]. Thus it is possible that $\beta$-arrestin or other phosphate-recognizing proteins also may directly interact with Fz.

Heterotrimeric $G$ proteins have been shown to directly interact with Fz receptors $[31,33]$ and to exchange their GDP for GTP upon interaction with the ligand-activated receptors [33-35]. Simple sequence alignment does not reveal $G$ protein-activating regions in the intracellular parts of Fzs. Different GPCRs expose different G protein-activating sequences, located mainly in the intracellular loops 2 and 3, and more rarely 1 and 4, upon structural rearrangements induced by agonists [95]. Thus Fz receptors likely have non-overlapping regions interacting with the two main types of intracellular transducers: Dvl binding to the C-terminus and $\mathrm{G}$ proteins to the intracellular loops. It remains unknown whether simultaneous Dvl and G protein binding to $\mathrm{Fz}$ is possible.

Heterotrimeric $G$ proteins are the most immediate transducers of GPCRs. About one thousand GPCRs are encoded by mammalian genomes, and roughly a dozen $\mathrm{G} \alpha$-subunits organize $\mathrm{G}$ protein complexes to transduce their signals. Thus it is obvious that many GPCRs signal through the same G proteins; additionally, a certain level of promiscuity exists, such that a receptor may talk to several different $G$ protein types [96]. Thus, the problem of how signal specificity is achieved can be raised and several ideas have been put forward to address this problem [97,98]. This issue is linked with the following question: can we reliably predict which $G$ proteins any given GPCR is coupled to? And if yes, can we extend this prediction capacity to Fz receptors?

A significant database of experimentally established links between different types of $G$ proteins and GPCRs has been collected in the previous 20 years. Analysis of these data shows that the specificity of GPCRs could not be deduced using conventional direct approaches to sequence comparison, as there is no single epitope which would be universally responsible for interaction with $G$ proteins. As a result, $G$-protein binding sites could be reliably predicted only for small groups of closely related receptors on the basis of existing biochemical data [99]. However, computational approaches have been developed for the broader groups of GPCRs, so that algorithms can be "taught" using the known receptor $-G$ protein combinations to predict those for primary sequences of other GPCRs [100-102].

The most efficient ( $94 \%$ accuracy) prediction tool to-date based on the neuronal network algorithm was developed in 2005 [101]; no Fz sequences were included in the training set of this tool. We used this tool to probe the coupling of $\mathrm{Fz}$ receptors to heterotrimeric $G$ proteins of different types. We find that all 10 human $\mathrm{Fz}$ proteins are predicted to be Go/i-family coupled, with the confidence value ranging from 0.88 to 0.99 (Table 1 ). Similar results were obtained for Drosophila receptors.

Table 1

Confidence of the coupling of 10 human and 2 Drosophila Frizzled receptors to Gi/oand $\mathrm{Gq}$-type heterotrimeric $\mathrm{G}$ proteins.

\begin{tabular}{lcc}
\hline & Gi/o & $\mathrm{Gq}$ \\
\hline Fz1 & 0.98 & $<0.5$ \\
Fz2 & 0.98 & $<0.5$ \\
Fz3 & 0.94 & $<0.5$ \\
Fz4 & 0.99 & 0.73 \\
Fz5 & 0.88 & 0.71 \\
Fz6 & 0.98 & 0.74 \\
Fz7 & 0.99 & $<0.5$ \\
Fz8 & 0.99 & $<0.5$ \\
Fz9 & 0.99 & $<0.5$ \\
Fz10 & 0.99 & $<0.5$ \\
dFz1 & 0.99 & 0.54 \\
dFz2 & 0.99 & $<0.5$ \\
\hline
\end{tabular}


Interestingly, no significant probability of signaling through the Gs- and G12/13-type of $G$ proteins was determined, while coupling to $\mathrm{Gq}$ was predicted to occur for $\mathrm{Fz} 4,5$ and 6 . In comparison to the results obtained with the earlier algorithms [39], our data display Fz as largely the Gi/o interacting family of receptors, in accordance with biochemical observations $[23,30,32-35,103,104]$. This brings us to the following question: What are the targets of these heterotrimeric G proteins in Fz signaling? As will be seen in the next section, relatively few effectors of the Gi/o proteins are known in general. However, novel transducers have recently emerged.

\section{The heterotrimeric Go protein: captain and his crew}

The heterotrimeric Go protein emerges as the major transducer of Fz across species [24,31,33,34]. G $\alpha$ o was among the first $\alpha$ subunits discovered, and was found to be the major $\mathrm{G} \alpha$-subunit of the nervous system across the animal kingdom [105,106], controlling both development and adult physiology of the brain $[107,108]$. Go is also required for the proper development and functioning of the heart $[109,110]$. In addition to the crucial developmental and physiological functions of this $G$ protein [111,112], it also has important pathological implications, especially in cancer [113]. Constitutive activation of Goo induced transformation in NIH-3T3 fibroblasts and tumors in mouse xenografts $[114,115]$. Recently, a mutation rendering G $\alpha$ o overly active [116] was described in human breast cancer samples and was shown to promote anchorage-independent growth of human mammary epithelial cells [117]. The oncogenic ability of G $\alpha$ o was proposed to involve activation of the Stat3 pathway [115], but is likely also to involve overactivation of the Wnt/Fz pathway [37]. The ability of G $\alpha$ o inhibitors to block the invasiveness of Wnt2transformed human colon cancer cells has been demonstrated [118].

Despite the evolutionary conserved function, abundance, and medical importance of the heterotrimeric Go protein, the list of its known molecular targets is remarkably short [119]. One of the described targets of G $\alpha$ o is RapGAPII - a GTPase-activating protein restricting the activity of the Ras-type small GTPase Rap1 $[120,121]$. G $\alpha$ o inhibits the negative action of RapGAPII, increasing the activity of Rap1 which in turn may lead to activation of the MAPK and Stat3 pathways [115,120]. RapGAPII interacts with Goo through the so-called GoLoco domain [121,122], present in many G $\alpha$ o/i-interacting proteins [123]. Another GoLoco domain-containing protein, Pins in Drosophila, GPR-1 in C. elegans, and AGS3/ LGN in mammals, has been shown to interact with Goo $[121,122,124]$. This interaction is necessary for asymmetric cell divisions in nematodes [125,126] and in Drosophila [25,121]. Goo has also been shown to interact with several RGS proteins [120,121]. Of those, RGS12/14 may represent not just a negative

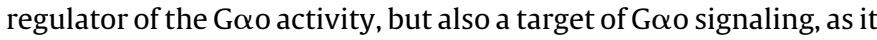
contains several additional protein-protein interaction regions, such as the PDZ and Rap-binding domains [127]. The latter may represent another link between G $\alpha$ o and MAPK signaling [128]; the importance of the interaction of Goo with loco (Drosophila RGS12/14 protein) has been demonstrated in the context of septate junction integrity in cardiac development [129]. In the mammalian brain, one of the G $\alpha$ o-interacting proteins is a major protein component of growth cones GAP-43 [130]. GAP-43 can activate guanine nucleotide exchange on G $\alpha 0$ in a GPCR-independent manner, which may be important for neurite extension $[108,130]$. Another brain protein capable of binding to and activating G $\alpha o$ is the amyloid precursor protein (APP) [131]. Although this interaction may have implications for the etiology of the Alzheimer's disease, the GEF activity of APP (and GAP-43) towards Goo indicate that these proteins are atypical activators, rather than targets, of Go-mediated GPCR signaling.
In essence, this description summarizes the body of existing knowledge concerning characterized interaction partners of Goo. The scarcity of the known targets has led to a proposition that the major mechanism of Go signaling is the release of $G \beta \gamma$ subunits from the heterotrimeric complex upon GPCR activation [132]. Indeed, in the brain $\mathrm{G} \beta \gamma$ released from the Go complex is able to regulate voltage-dependent $\mathrm{Ca}^{2+}$ channels, as well as inward-rectifier $\mathrm{K}^{+}$ channels [132]. However, through several broad screening approaches we have identified a massive network of G $\alpha$ o-centered protein-protein interactions ([121,133] and unpublished data). Two novel G $\alpha$ o target proteins will be reviewed below: Rab5 and Axin.

\section{Frizzleds and Rab-family monomeric GTPases: submerging with the signaling endosomes}

GPCR internalization plays important roles in the regulation of the receptor signaling [134]. It may simply function to deplete GPCRs from the plasma membranes and thus shut the signaling off. Alternatively, through receptor recycling back to the plasma membrane, it may serve to ready the cell for the new round of agonist stimulation. If recycling is preceded by directed transport of the GPCR endosomes, this combined activity can elicit accumulation of the receptors in a particular domain of the plasma membrane, which may be required for cell polarization. Finally, in certain cases internalization produces the so-called signaling endosomes, from which the ligand-receptor complexes continue to signal inside the cell, often with an enhanced strength or changed modality.

Fz receptors are also tightly regulated by endocytosis. In the canonical $\beta$-catenin-dependent signaling, internalization of Fz was proposed to enhance the initial signal emanating from the plasma membrane $[65,135,136]$. In the PCP branch of the pathway, Fz is endocytosed and transported along microtubules to be released at the apical posterior membrane to elicit planar polarization of the epithelia [81]. Out of the many possible endocytosis routes [137], two have been implicated in Fz regulation: clathrin-dependent and caveolin-dependent endocytosis [138,139]. Clathrin-mediated internalization of $\mathrm{Fz}$ relies on Dvl and $\beta$-arrestin as discussed above [89-91], as well as on the $\mu$-subunit of the adaptor complex 2 (AP-2) linking Dvl with clathrin; these interactions are required for the proper PCP signaling [140]. Both clathrin-dependent and caveolin-dependent endocytosis have been shown necessary also for the canonical Wnt/Fz signaling [136,141]. Similarly, the more downstream endocytic components, common for both internalization routes, have been implicated in Fz signaling. Dynamin, required for pinching off of the plasma membrane invaginations to form early endocytic vesicles has been shown to be required for the high levels of the canonical Wnt signaling [135], although conflicting data exist on its role in this pathway [138]. Finally, Rab5, the small GTPase responsible for the regulation of a number of early endocytic events, such as formation of clathrin-coated vesicles, fusion of endocytic vesicles and early endosomes, and homotypic fusion between early endosomes [142], is required for both the canonical and PCP Fz signaling [65,135].

In addition to Rab5, a number of other Rab proteins regulate GPCR trafficking. Specifically, Rab4 mediates the fast recycling of endosomes back to the plasma membrane, while Rab11 is responsible for the slower recycling path. In contrast, Rab7 controls transition from the early to late endosomes, destining the receptors for lysosomal degradation [142]. Relatively little is known about whether GPCRs or their signaling components can regulate these different Rab activities and thus influence their own trafficking fates. We have provided a mechanistic description of how Fz and G $\alpha 0$ as its immediate binding partner regulate Rab GTPases to differentially affect signaling in the canonical and PCP branches [65]. 
We have found that Fz proteins in Drosophila (dFz1 and dFz2) can interact with Rab5 genetically as well as physically as recombinant proteins [65]. This direct binding of GPCRs to a Rab protein is not unprecedented: angiotensin II type $1 \mathrm{~A}$ receptor through its C-terminus binds Rab5, Rab4 and Rab11 and thus influences its own trafficking [143,144], while tromboxan $A_{2}$ and $\beta 2$-adrenergic receptors have been shown to interact with Rab11 $[145,146]$. Interestingly, we have additionally found that the immediate Fz transducer G $\alpha$ o also binds Rab4 and Rab5, but not Rab11 [65]. This is the first ever demonstration of a direct interaction between an $\alpha$-subunit of heterotrimeric $G$ proteins and small GTPases of the Rab family. In vitro, Rab5-GDP is the preferable binding partner of $\mathrm{G} \alpha$ o hinting at the potential of $\mathrm{G} \alpha \mathrm{o}$ to activate Rab5. And indeed we find in cellular assays that Goo activates Rab5; Fz proteins can do the same in the Goo-dependent manner [65]. We provide evidence that the mechanism for the $\mathrm{G} \alpha-$ induced Rab5 activation is the recruitment of the latter from the cytoplasm to the plasma membrane, where the natural Rab5 GEFs such as Rabex 5 are localized $[65,147]$. Through this relocalization, Rab5 is activated in the vicinity of Fz receptors, inducing their internalization [65]. Since internalized $\mathrm{Fz}$ complexes possess the maximal signaling strength $[135,136]$, the Fz-Goo-Rab5 relay serves as amplifier of the initial plasma membrane-originated signal in the canonical Wnt pathway [65]. Similarly, in the PCP branch of Fz signaling, this internalization, followed by microtubule-dependent transport [81] and Rab11-mediated recycling [65], is responsible for the enhanced receptor signaling.

In addition to the discovery of an intricate mechanism of GPCRmediated regulation of trafficking, and trafficking-mediated regulation of GPCR signaling, our studies provide insights into the details of Fz receptor signaling. The first relates to the question how the cell decides which subpathway - canonical vs PCP - is activated, if the same receptor (dFz1 in Drosophila) can activate both pathways. Several contradicting ideas have been put forward to address this question $[41,148,149]$. Our findings suggest that $\mathrm{Fz}$ is directed to one or the other subpathway through different trafficking routes. Specifically, Rab5-dependent endocytosis, opposed by Rab4- and Rab11-mediated recycling, is required for maximization of $\mathrm{Fz}$ signaling in the canonical pathway. In contrast, Rab5-dependent endocytosis and Rab11-dependent slow recycling is the trafficking route required for the strong PCP signaling. Thus, G $\alpha$ o, Rab5 and the recycling Rabs play the role of the pointsman, subdividing the Fz signaling into canonical and PCP subpathways [65].

Another interesting finding relates to the distinct signaling abilities of Drosophila dFz1 and dFz2 receptors. Only dFz1 is active in PCP signaling, but both are competent in the Wingless $(\mathrm{Wg}$, Drosophila Wnt-1) transduction $[9,150,151]$. However even in this canonical signaling the two receptors bear clear signaling differences. For example, overexpressed $\mathrm{dFz} 2$ can potently overactivate the Wg pathway and induce ectopic sensory bristles in Drosophila wings, while dFz1 is ineffective in such overactivation $[41,148,149,152]$. We believe that these differences originate from the unequal activities of the two receptors in the activation of Rab5 and endocytosis. We have found that dFz2 has a strong basal, ligand-independent capacity to activate endocytosis, which is only modestly stimulated by Wg. In contrast, $\mathrm{dFz} 1$ in the absence of the ligand is mediocre in enhancing the endocytic potential of the cell, but becomes fully active in the presence of the Wg ligand [65]. Both receptors are dependent on G $\alpha$ o for this stimulation of endocytosis [65]. In the developing Drosophila wing, $\mathrm{Wg}$ is produced by a narrow stripe of cells along the dorso-ventral margin - the future adult wing margin. Being a poorly diffusive morphogen, $\mathrm{Wg}$ concentrates close to the zone of production and its concentration in the rest of the growing wing tissue is low $[58,153]$. Thus dFz1, overexpressed in the regions of low $\mathrm{Wg}$ concentration, is poorly active in inducing its own endocytosis and cannot lead to endosome-directed high levels of signaling, necessary for induction of the high-threshold target genes such as Senseless required for the bristle development. In contrast, $\mathrm{dFz} 2$ overexpression in the same domain leads to the general stimulation of endocytosis, dFz2 internalization, and strong endosome-directed signaling. (Of note, endogenous $\mathrm{dFz} 2$ expression is low in the tissue away from the source of $\mathrm{Wg}$ production, as opposed to $\mathrm{dFz} 1$ which is ubiquitously expressed across the tissue [152].) Thus, our data provide the mechanistic explanation, in terms of differences in their basal vs ligand-stimulated Rab5 activation, to the long-known differences in the activities of $\mathrm{Fz}$ receptors [65].

\section{Axin as Neptune of the deep-water Wnt/Frizzled signaling: the many ways to appease the evil god}

Since Rab5 appears as an amplifier of the Fz-Go signaling, other effector(s) of Go must exist in this pathway, directly transducing the initial Wnt signal towards the downstream signaling machinery. We have identified Axin as one of such transducers [64]. Axin is the key negative regulator of the canonical Wnt pathway, capable of interacting with many proteins and organizing the $\beta$-catenin destruction complex [154]. Binding of the Wnt ligand to its receptors leads to reorganization of this complex through several signaling inputs into the Axin protein. One is provided by LRP5/6, which can directly bind Axin upon phosphorylation by casein kinase 1 and GSK3 [155-158]. The second input is mediated by Dvl, which inactivates Axin through the heterophilic interaction of the DIX domains present in both proteins $[78,79]$. This action of Dvl may in turn be enhanced by the $\beta \gamma$-subunits of the heterotrimeric $G$ proteins, which bring Dvl to the plasma membrane $[64,159,160]$. Finally, the novel mechanism contributing to the neutralization of Axin is mediated by G $\alpha$ o [64]. This $\alpha$-subunit, released from the heterotrimeric Go complex by the activity of Fz receptors, directly binds Axin through its RGS domain, recruits it from the cytoplasm and thus suppresses its negative activity in the Wnt signaling [64].

Although it is probable that the three mechanisms act in parallel, they may be differentially involved in different modes of the canonical Wnt/Fz signaling. This idea brings us again to the issue of different cellular compartments, from which this signaling can emanate: low-level signaling from the plasma membrane vs high-level signaling from Rab5-positive endosomes. It is conceivable that different molecular components of the Wnt/Fz transduction machinery are involved in signaling from these two compartments, with different outcomes. For example, speaking about the developing insect wing as the read-out for Wnt signaling, it can be proposed that the plasma membrane-originating lowlevel signaling leads to expression of the low-threshold Wnt target genes Distal-less and Vestigial. In contrast, the endosomeoriginating high-level signaling drives expression of the highthreshold Wnt target Senseless and subsequent development of the sensory wing bristles. It also appears that the heterotrimeric Go protein is crucial for the signaling from the plasma membrane, but not the endosome (although it is required for the proper trafficking of $\mathrm{Fz}$ from the plasma membrane to endosomes). Indeed, overexpression of $\mathrm{G} \alpha \mathrm{O}$ or its constitutively active mutant form could induce low-threshold Wnt target genes Distal-less and Vestigial, but not high-threshold targets like Senseless; as a result, no ectopic margin bristles are ever produced by Goo overexpression [24]. Similarly, different forms of Axin show different effects regarding the high- and the low-threshold Wnt target genes: while overexpression of full-length Axin induced a complete loss of both types of Wnt target genes, the Axin $\Delta$ RGS construct resulted in a complete loss of Senseless expression in wings (and failure of bristle development), but did not at all affect the expression of the low-threshold target gene Distal-less [64]. As the RGS domain is 
absolutely required for the interaction with $\mathrm{G} \alpha \mathrm{o}$, these data cumulatively suggest that the Goo-mediated impact on Axin is required for the plasma membrane-originating low-level signaling, leading to expression of the low-threshold Wnt targets like Distal-less. In contrast, the endosome-originating high levels of Wnt signaling apparently rely on Goo-independent inputs into Axin to result in expression of the high-threshold target genes.

The distinction between the low-level plasma membrane signaling and the high-level endosome signaling may also be temporal: it is clear that the first precedes the second, and indeed different temporal phases in the Wnt/Fz signaling can be identified $[31,161]$. It should also be remembered that different packaging forms of Wnt ligands exist, destined for short vs long-range diffusion through the tissue and resulting in expression of different target genes [58]. It remains to be clarified whether these different forms induce different subtypes of intracellular signaling.

The data summarized above identify Axin as an effector in $\mathrm{Fz} /$

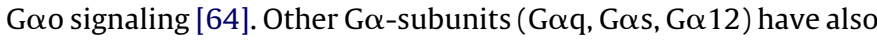
been proposed to interact with Axin isoforms, suggesting that nonFz GPCRs may also feed into this scaffolding protein [31,162,163]. On the other hand, Dvl may also emerge as a more general GPCR effector, directly interacting with the PDZ-binding motif of multiple GPCRs [164]. Moreover, G $\beta \gamma$ subunits can bind and regulate Dvl in different organisms $[64,159,160]$; $\mathrm{G} \alpha$-subunits also have a potential to interact with it (our unpublished observations). It is worth adding that Dvl can multimerize, incorporating Axin and other proteins into giant signalosomes [79,165-168]. It remains to be established whether such Dvl-based signalosomes and Axinbased protein complexes may represent a novel type of effectors in many GPCR signaling pathways.

\section{Conclusions}

Receptors of the Fz family, recognizing the Wnt growth factors and initiating developmentally and medically important cellular signaling pathways, have been acknowledged as potential GPCRs ever since their discovery $[9,10]$. However, it took decades of research to prove that heterotrimeric $G$ proteins are required for the normal Wnt/Fz signaling in various organisms (reviewed in $[37,111])$. And only recently the final biochemical proof for the GPCR activity of Fzs has been provided [33-35], resolving the debate of whether Fz proteins are bona fide GPCRs [37]. Novel effectors of $G$ proteins in the Fz pathways are emerging, such as the small GTPase Rab5 acting as the amplifier of signaling [65], and Axin as the key negative player in transduction, scaffold for multiple regulatory inputs including the one mediated by G $\alpha 0$ [64]. At the same time, it is clear that Fz pathways are complicated enough to utilize other, G protein-independent, ways to transmit the signal inside the cell [48], as is also the case for other GPCRs [169]. Different cellular compartments, different temporal phases of the signaling, and finally different forms of Wnt ligands may differentially depend on various Fz transducers. The discovery of the $G$ protein-coupled mechanisms and targets of $\mathrm{Fz}$ signaling brings along further mechanistic understanding of this type of intracellular signaling. Additionally, it opens the way to utilize the vast GPCR methodology towards Fz proteins in the drug discovery endeavors, with the goal of obtaining small molecule antagonists as potential anti-cancer drugs, and agonists as agents for regenerative medicine $[6,50,170]$.

\section{Acknowledgements}

The work was supported by the Deutsche Forschungsgemeinschaft (grants TR-SFB11 and KA 2721/1-1) to V.L.K. We thank Anne-Marie Luechtenborg and Chen Lin for critical reading of the manuscript.

\section{References}

[1] Logan CY, Nusse R. The Wnt signaling pathway in development and disease. Annu Rev Cell Dev Biol 2004;20:781-810.

[2] Zhao J, Kim KA, Abo A. Tipping the balance: modulating the Wnt pathway for tissue repair. Trends Biotechnol 2009;27:131-6.

[3] Nusse R, Fuerer C, Ching W, Harnish K, Logan C, Zeng A, et al. Wnt signaling and stem cell control. Cold Spring Harb Symp Quant Biol 2008;73:59-66.

[4] De Ferrari GV, Moon RT. The ups and downs of Wnt signaling in prevalent neurological disorders. Oncogene 2006;25:7545-53.

[5] Giles RH, van Es JH, Clevers H. Caught up in a Wnt storm: Wnt signaling in cancer. Biochim Biophys Acta 2003;1653:1-24.

[6] Barker N, Clevers H. Mining the Wnt pathway for cancer therapeutics. Nat Rev Drug Discov 2006;5:997-1014.

[7] Adler PN. Planar signaling and morphogenesis in Drosophila. Dev Cell 2002;2:525-35

[8] Bhanot P, Brink M, Samos CH, Hsieh JC, Wang Y, Macke JP, et al. A new member of the Frizzled family from Drosophila functions as a Wingless receptor. Nature 1996;382:225-30.

[9] Vinson CR, Conover S, Adler PN. A Drosophila tissue polarity locus encodes a protein containing seven potential transmembrane domains. Nature 1989;338:263-4.

[10] Adler PN, Vinson C, Park WJ, Conover S, Klein L. Molecular structure of Frizzled, a Drosophila tissue polarity gene. Genetics 1990;126:401-16.

[11] Unwin PN, Henderson R. Molecular structure determination by electron microscopy of unstained crystalline specimens. J Mol Biol 1975;94:425-40.

[12] Ovchinnikov Iu A, Abdulaev NG, Feigina M, Artamonov ID, Bogachuk AS Visual rhodopsin. III. Complete amino acid sequence and topography in a membrane. Bioorg Khim 1983;9:1331-40.

[13] Hargrave PA, McDowell JH, Curtis DR, Wang JK, Juszczak E, Fong SL, et al. The structure of bovine rhodopsin. Biophys Struct Mech 1983;9:235-44.

[14] Dixon RA, Kobilka BK, Strader DJ, Benovic JL, Dohlman HG, Frielle T, et al. Cloning of the gene and cDNA for mammalian beta-adrenergic receptor and homology with rhodopsin. Nature 1986;321:75-9.

[15] Millar RP, Newton CL. The year in G protein-coupled receptor research. Mol Endocrinol 2010;24:261-74.

[16] Cabrera-Vera TM, Vanhauwe J, Thomas TO, Medkova M, Preininger A, Mazzoni MR, et al. Insights into $G$ protein structure, function, and regulation. Endocr Rev 2003;24:765-81.

[17] Kenakin T. Ligand-selective receptor conformations revisited: the promise and the problem. Trends Pharmacol Sci 2003;24:346-54.

[18] Clapham DE, Neer EJ. G protein beta gamma subunits. Annu Rev Pharmacol Toxicol 1997; 37:167-203.

[19] Atwood BK, Lopez J, Wager-Miller J, Mackie K, Straiker A. Expression of G protein-coupled receptors and related proteins in HEK293, AtT20, BV2, and N18 cell lines as revealed by microarray analysis. BMC Genomics 2011;12:14

[20] Peifer M, Rauskolb C, Williams M, Riggleman B, Wieschaus E. The segment polarity gene armadillo interacts with the wingless signaling pathway in both embryonic and adult pattern formation. Development 1991;111:1029-43.

[21] Klingensmith J, Nusse R, Perrimon N. The Drosophila segment polarity gene dishevelled encodes a novel protein required for response to the wingless signal. Genes Dev 1994;8:118-30.

[22] Papkoff J, Rubinfeld B, Schryver B, Polakis P. Wnt-1 regulates free pools of catenins and stabilizes APC-catenin complexes. Mol Cell Biol 1996;16:2128-34.

[23] Slusarski DC, Corces VG, Moon RT. Interaction of Wnt and a Frizzled homologue triggers G-protein-linked phosphatidylinositol signalling. Nature 1997;390:410-3.

[24] Katanaev VL, Ponzielli R, Semeriva M, Tomlinson A. Trimeric G proteindependent Frizzled signaling in Drosophila. Cell 2005;120:111-22.

[25] Katanaev VL, Tomlinson A. Dual roles for the trimeric G protein Go in asymmetric cell division in Drosophila. Proc Natl Acad Sci USA 2006;103:6524-9.

[26] Katanaev VL, Tomlinson A. Multiple roles of a trimeric G protein in Drosophila cell polarization. Cell Cycle 2006;5:2464-72.

[27] Jernigan KK, Cselenyi CS, Thorne CA, Hanson AJ, Tahinci E, Hajicek N, et al. Gbetagamma activates GSK3 to promote LRP6-mediated beta-catenin transcriptional activity. Sci Signal 2010;3:ra37.

[28] Salmanian S, Najafi SM, Rafipour M, Arjomand MR, Shahheydari H, Ansari S, et al. Regulation of GSK-3beta and beta-Catenin by Galphaq in HEK293T cells. Biochem Biophys Res Commun 2010;395:577-82.

[29] Liu X, Liu T, Slusarski DC, Yang-Snyder J, Malbon CC, Moon RT, et al. Activation of a Frizzled-2/beta-adrenergic receptor chimera promotes Wnt signaling and differentiation of mouse F9 teratocarcinoma cells via Galphao and Galphat. Proc Natl Acad Sci USA 1999;96:14383-8.

[30] Liu T, DeCostanzo AJ, Liu X, Wang H, Hallagan S, Moon RT, et al. G protein signaling from activated rat Frizzled-1 to the beta-catenin-Lef-Tcf pathway. Science 2001;292:1718-22.

[31] Liu X, Rubin JS, Kimmel AR. Rapid, Wnt-induced changes in GSK3beta associations that regulate beta-catenin stabilization are mediated by Galpha proteins. Curr Biol 2005;15:1989-97.

[32] Bikkavilli RK, Feigin ME, Malbon CC. G\{alpha\}o mediates WNT-JNK signaling through Dishevelled 1 and 3, RhoA family members, and MEKK 1 and 4 in mammalian cells. J Cell Sci 2008;121:234-45.

[33] Katanaev VL, Buestorf S. Frizzled proteins are bonafide G protein-coupled receptors. Available from Nature Precedings: http://hdlhandlenet/10101/ npre200927651; 2009. 
[34] Koval A, Katanaev VL. Wnt3a stimulation elicits G-protein-coupled receptor properties of mammalian Frizzled proteins. Biochem J 2011;433:435-40.

[35] Kilander MB, Dijksterhuis JP, Ganji RS, Bryja V, Schulte G. WNT-5A stimulates the GDP/GTP exchange at pertussis toxin-sensitive heterotrimeric $G$ proteins. Cell Signal 2011;23:550-4.

[36] Malbon CC. Wnt signalling: the case of the 'missing' G-protein. Biochem J 2011;433:e3-5.

[37] Egger-Adam D, Katanaev VL. Trimeric G protein-dependent signaling by Frizzled receptors in animal development. Front Biosci 2008;13:4740-55.

[38] Katanaev VL. The Wnt/frizzled GPCR signaling pathway. Biochemistry (Mosc) 2010;75:1428-34.

[39] Wang HY, Liu T, Malbon CC. Structure-function analysis of Frizzleds. Cell Signal 2006;18:934-41.

[40] Xu YK, Nusse R. The Frizzled CRD domain is conserved in diverse proteins including several receptor tyrosine kinases. Curr Biol 1998;8:R405-6.

[41] Rulifson EJ, Wu CH, Nusse R. Pathway specificity by the bifunctional receptor frizzled is determined by affinity for wingless. Mol Cell 2000;6:117-26.

[42] Wu CH, Nusse R. Ligand receptor interactions in the Wnt signaling pathway in Drosophila. J Biol Chem 2002;277:41762-9.

[43] Kawano Y, Kypta R. Secreted antagonists of the Wnt signalling pathway. J Cell Sci 2003;116:2627-34

[44] Alcedo J, Ayzenzon M, Von Ohlen T, Noll M, Hooper JE. The Drosophila smoothened gene encodes a seven-pass membrane protein, a putative receptor for the hedgehog signal. Cell 1996;86:221-32.

[45] Chen CM, Strapps W, Tomlinson A, Struhl G. Evidence that the cysteine-rich domain of Drosophila Frizzled family receptors is dispensable for transducing Wingless. Proc Natl Acad Sci USA 2004;101:15961-6.

[46] Katanaev VL. Signal transduction in neutrophil chemotaxis. Biochemistry (Mosc) 2001;66:351-68.

[47] van Amerongen R, Mikels A, Nusse R. Alternative wnt signaling is initiated by distinct receptors. Sci Signal 2008;1:re9.

[48] van Amerongen R, Nusse R. Towards an integrated view of Wnt signaling in development. Development 2009;136:3205-14.

[49] Koval A, Kopein D, Purvanov V, Katanaev VL. Europium-labeled GTP as a general nonradioactive substitute for [(35)S]GTPgammaS in high-throughput G protein studies. Anal Biochem 2010;397:202-7.

[50] Katanaev VL. Assay for monitoring activity of frizzled receptors. Eur Pat Appl, EP2048503, 2009.

[51] Grumolato L, Liu G, Mong P, Mudbhary R, Biswas R, Arroyave R, et al. Canonical and noncanonical Wnts use a common mechanism to activate completely unrelated coreceptors. Genes Dev 2010;24:2517-30.

[52] Tamai K, Semenov M, Kato Y, Spokony R, Liu C, Katsuyama Y, et al. LDL-receptorrelated proteins in Wnt signal transduction. Nature 2000;407:530-5.

[53] Wan M, Li J, Herbst K, Zhang J, Yu B, Wu X, et al. LRP6 mediates cAMP generation by $\mathrm{G}$ protein-coupled receptors through regulating the membrane targeting of Galpha(s). Sci Signal 2011;4:ra15.

[54] Wan M, Yang C, Li J, Wu X, Yuan H, Ma H, et al. Parathyroid hormone signaling through low-density lipoprotein-related protein 6 . Genes Dev 2008:22:2968-79.

[55] Parameswaran N, Spielman WS. RAMPs: the past, present and future. Trends Biochem Sci 2006;31:631-8.

[56] Willnow TE, Hammes A, Eaton S. Lipoproteins and their receptors in embryonic development: more than cholesterol clearance. Development 2007:134:3239-49.

[57] Panakova D, Sprong H, Marois E, Thiele C, Eaton S. Lipoprotein particles are required for Hedgehog and Wingless signalling. Nature 2005;435:58-65.

[58] Katanaev VL, Solis GP, Hausmann G, Buestorf S, Katanayeva N, Schrock Y, et al. Reggie-1/flotillin-2 promotes secretion of the long-range signalling forms of Wingless and Hedgehog in Drosophila. EMBO J 2008;27:509-21.

[59] Eaton S. Release and trafficking of lipid-linked morphogens. Curr Opin Genet Dev 2006;16:17-22.

[60] Willert K, Brown JD, Danenberg E, Duncan AW, Weissman IL, Reya T, et al. Wnt proteins are lipid-modified and can act as stem cell growth factors. Nature 2003;423:448-52.

[61] Coudreuse D, Korswagen HC. The making of Wnt: new insights into Wnt maturation, sorting and secretion. Development 2006.

[62] Port F, Basler K. Wnt trafficking: new insights into Wnt maturation, secretion and spreading. Traffic 2010;11:1265-71.

[63] Morrell NT, Leucht P, Zhao L, Kim JB, ten Berge D, Ponnusamy K, et al. Liposomal packaging generates Wnt protein with in vivo biological activity. PLoS One 2008;3:e2930.

[64] Egger-Adam D, Katanaev VL. The trimeric G protein Go inflicts a double impact on axin in the Wnt/frizzled signaling pathway. Dev Dyn 2010;239:168-83.

[65] Purvanov V, Koval A, Katanaev VL. A direct and functional interaction between Go and Rab5 during $G$ protein-coupled receptor signaling. Sci Signal 2010;3:ra65.

[66] Franco R, Casado V, Cortes A, Ferrada C, Mallol J, Woods A, et al. Basic concepts in G-protein-coupled receptor homo- and heterodimerization. Scientific World J 2007;7:48-57.

[67] Dann CE, Hsieh JC, Rattner A, Sharma D, Nathans J, Leahy DJ. Insights into Wnt binding and signalling from the structures of two Frizzled cysteine-rich domains. Nature 2001;412:86-90.

[68] Carron C, Pascal A, Djiane A, Boucaut JC, Shi DL, Umbhauer M. Frizzled receptor dimerization is sufficient to activate the $\mathrm{Wnt} /$ beta-catenin pathway. J Cell Sci 2003;116:2541-50.
[69] Kaykas A, Yang-Snyder J, Heroux M, Shah KV, Bouvier M, Moon RT. Mutant Frizzled 4 associated with vitreoretinopathy traps wild-type Frizzled in the endoplasmic reticulum by oligomerization. Nat Cell Biol 2004;6:52-8.

[70] Kristiansen K. Molecular mechanisms of ligand binding, signaling, and regulation within the superfamily of G-protein-coupled receptors: molecular modeling and mutagenesis approaches to receptor structure and function. Pharmacol Ther 2004;103:21-80.

[71] George SR, O'Dowd BF, Lee SP. G-protein-coupled receptor oligomerization and its potential for drug discovery. Nat Rev Drug Discov 2002;1:808-20.

[72] Umbhauer M, Djiane A, Goisset C, Penzo-Mendez A, Riou JF, Boucaut JC, et al. The C-terminal cytoplasmic Lys-thr-X-X-X-Trp motif in frizzled receptors mediates Wnt/beta-catenin signalling. EMBO J 2000;19:4944-54.

[73] Punchihewa C, Ferreira AM, Cassell R, Rodrigues P, Fujii N. Sequence requirement and subtype specificity in the high-affinity interaction between human frizzled and dishevelled proteins. Protein Sci 2009;18:994-1002.

[74] Malbon CC, Wang HY. Dishevelled: a mobile scaffold catalyzing development. Curr Top Dev Biol 2006;72:153-66.

[75] Gao C, Chen YG. Dishevelled: the hub of Wnt signaling. Cell Signal 2010;22:717-27.

[76] Kishida S, Yamamoto H, Hino S, Ikeda S, Kishida M, Kikuchi A. DIX domains of Dvl and axin are necessary for protein interactions and their ability to regulate beta-catenin stability. Mol Cell Biol 1999;19:4414-22.

[77] Fagotto F, Jho E, Zeng L, Kurth T, Joos T, Kaufmann C, et al. Domains of axin involved in protein-protein interactions. Wnt pathway inhibition, and intracellular localization. J Cell Biol 1999;145:741-56.

[78] Cliffe A, Hamada F, Bienz M. A role of Dishevelled in relocating Axin to the plasma membrane during wingless signaling. Curr Biol 2003;13:960-6.

[79] Schwarz-Romond T, Metcalfe C, Bienz M. Dynamic recruitment of axin by Dishevelled protein assemblies. J Cell Sci 2007;120:2402-12.

[80] Axelrod JD. Unipolar membrane association of Dishevelled mediates Frizzled planar cell polarity signaling. Genes Dev 2001;15:1182-7.

[81] Shimada Y, Yonemura S, Ohkura H, Strutt D, Uemura T. Polarized transport of Frizzled along the planar microtubule arrays in Drosophila wing epithelium. Dev Cell 2006;10:209-22.

[82] Tan C, Deardorff MA, Saint-Jeannet JP, Yang J, Arzoumanian A, Klein PS. Kermit, a frizzled interacting protein, regulates frizzled 3 signaling in neural crest development. Development 2001;128:3665-74.

[83] Luyten A, Mortier E, Van Campenhout C, Taelman V, Degeest G, Wuytens G, et al. The postsynaptic density $95 /$ disc-large/zona occludens protein syntenin directly interacts with frizzled 7 and supports noncanonical Wnt signaling. Mol Biol Cell 2008;19:1594-604.

[84] Yao R, Maeda T, Takada S, Noda T. Identification of a PDZ domain containing Golgi protein, GOPC, as an interaction partner of frizzled. Biochem Biophys Res Commun 2001;286:771-8.

[85] Feigin ME, Malbon CC. RGS19 regulates Wnt-beta-catenin signaling through inactivation of Galpha(o). J Cell Sci 2007;120:3404-14.

[86] De Vries L, Lou X, Zhao G, Zheng B, Farquhar MG. GIPC, a PDZ domain containing protein, interacts specifically with the $C$ terminus of RGS-GAIP. Proc Natl Acad Sci USA 1998;95:12340-5.

[87] Neudauer CL, Joberty G, Macara IG. PIST: a novel PDZ/coiled-coil domain binding partner for the rho-family GTPase TC10. Biochem Biophys Res Commun 2001;280:541-7.

[88] DeWire SM, Ahn S, Lefkowitz RJ, Shenoy SK. Beta-arrestins and cell signaling. Annu Rev Physiol 2007:69:483-510.

[89] Chen W, Hu LA, Semenov MV, Yanagawa S, Kikuchi A, Lefkowitz RJ, et al. betaArrestin1 modulates lymphoid enhancer factor transcriptional activity through interaction with phosphorylated dishevelled proteins. Proc Natl Acad Sci USA 2001;98:14889-94.

[90] Chen W, ten Berge D, Brown J, Ahn S, Hu LA, Miller WE, et al. Dishevelled 2 recruits beta-arrestin 2 to mediate Wnt5A-stimulated endocytosis of Frizzled 4. Science 2003;301:1391-4.

[91] Bryja V, Gradl D, Schambony A, Arenas E, Schulte G. Beta-arrestin is a necessary component of Wnt/beta-catenin signaling in vitro and in vivo. Proc Natl Acad Sci USA 2007;104:6690-5.

[92] Chen M, Philipp M, Wang J, Premont RT, Garrison TR, Caron MG, et al. G Protein-coupled receptor kinases phosphorylate LRP6 in the Wnt pathway. J Biol Chem 2009;284:35040-8.

[93] Yanfeng WA, Tan C, Fagan RJ, Klein PS. Phosphorylation of frizzled-3. J Biol Chem 2006;281:11603-9.

[94] Djiane A, Yogev S, Mlodzik M. The apical determinants aPKC and dPatj regulate Frizzled-dependent planar cell polarity in the Drosophila eye. Cell 2005;121:621-31.

[95] Oldham WM, Hamm HE. How do receptors activate G proteins? Adv Protein Chem 2007;74:67-93.

[96] Hermans E. Biochemical and pharmacological control of the multiplicity of coupling at G-protein-coupled receptors. Pharmacol Ther 2003;99:25-44.

[97] Ferguson SS. Evolving concepts in G protein-coupled receptor endocytosis: the role in receptor desensitization and signaling. Pharmacol Rev 2001;53: $1-24$.

[98] Katanaev VL, Chornomorets M. Kinetic diversity in G-protein-coupled receptor signalling. Biochem J 2007;401:485-95.

[99] Wess J. Molecular basis of receptor/G-protein-coupling selectivity. Pharmacol Ther 1998;80:231-64.

[100] Moller S, Vilo J, Croning MD. Prediction of the coupling specificity of G protein coupled receptors to their $G$ proteins. Bioinformatics 2001;17(Suppl. 1):S174-81. 
[101] Sgourakis NG, Bagos PG, Hamodrakas SJ. Prediction of the coupling specificity of GPCRs to four families of G-proteins using hidden Markov models and artificial neural networks. Bioinformatics 2005;21:4101-6.

[102] Guo Y, Li M, Lu M, Wen Z, Huang Z. Predicting G-protein coupled receptors-Gprotein coupling specificity based on autocross-covariance transform. Proteins 2006;65:55-60.

[103] Liu T, Liu X, Wang H, Moon RT, Malbon CC. Activation of rat frizzled-1 promotes Wnt signaling and differentiation of mouse F9 teratocarcinoma cells via pathways that require Galpha(q) and Galpha(o) function. J Biol Chem 1999;274:33539-44.

[104] Ahumada A, Slusarski DC, Liu X, Moon RT, Malbon CC, Wang HY. Signaling of rat Frizzled-2 through phosphodiesterase and cyclic GMP. Science 2002;298:2006-10.

[105] Sternweis PC, Robishaw JD. Isolation of two proteins with high affinity for guanine nucleotides from membranes of bovine brain. J Biol Chem 1984;259:13806-13.

[106] Wolfgang WJ, Quan F, Goldsmith P, Unson C, Spiegel A, Forte M. Immunolocalization of G protein alpha-subunits in the Drosophila CNS. J Neurosci 1990;10:1014-24.

[107] Jiang M, Gold MS, Boulay G, Spicher K, Peyton M, Brabet P, et al. Multiple neurological abnormalities in mice deficient in the $G$ protein Go. Proc Nat Acad Sci USA 1998;95:3269-74.

[108] Bromberg KD, lyengar R, He JC. Regulation of neurite outgrowth by G(i/o) signaling pathways. Front Biosci 2008;13:4544-57.

[109] Valenzuela D, Han X, Mende U, Fankhauser C, Mashimo H, Huang P, et al. alpha(o) is necessary for muscarinic regulation of $\mathrm{Ca}^{2+}$ channels in mouse heart. Proc Natl Acad Sci USA 1997;94:1727-32.

[110] Fremion F, Astier M, Zaffran S, Guillen A, Homburger V, Semeriva M. The heterotrimeric protein Go is required for the formation of heart epithelium in Drosophila. J Cell Biol 1999;145:1063-76.

[111] Malbon CC. G proteins in development. Nat Rev Mol Cell Biol 2005;6: 689-701.

[112] Wettschureck N, Offermanns S. Mammalian G proteins and their cell type specific functions. Physiol Rev 2005;85:1159-204.

[113] Entschladen F, Zanker KS, Powe DG. Heterotrimeric G protein signaling in cancer cells with regard to metastasis formation. Cell Cycle 2011;10: 1086-91.

[114] Kroll SD, Chen J, De Vivo M, Carty DJ, Buku A, Premont RT, et al. The Q205LGoalpha subunit expressed in NIH-3T3 cells induces transformation. J Biol Chem $1992 \cdot 267 \cdot 23183-8$

[115] Ram PT, Horvath CM, Iyengar R. Stat3-mediated transformation of NIH-3T3 cells by the constitutively active Q205L Galphao protein. Science 2000;287:142-4

[116] Garcia-Marcos M, Ghosh P, Farquhar MG. Molecular basis of a novel oncogenic mutation in GNAO1. Oncogene 2011.

[117] Kan Z, Jaiswal BS, Stinson J, Janakiraman V, Bhatt D, Stern HM, et al. Diverse somatic mutation patterns and pathway alterations in human cancers. Nature 2010;466:869-73.

[118] Prevost GP, Lonchampt MO, Holbeck S, Attoub S, Zaharevitz D, Alley M, et al. Anticancer activity of BIM-46174, a new inhibitor of the heterotrimeric Galpha/Gbetagamma protein complex. Cancer Res 2006;66:9227-34.

[119] Jiang M, Bajpayee NS. Molecular mechanisms of go signaling. Neurosignals 2009;17:23-41.

[120] Jordan JD, Carey KD, Stork PJ, Iyengar R. Modulation of rap activity by direct interaction of Galpha(o) with Rap1 GTPase-activating protein. J Biol Chem 1999;274:21507-10.

[121] Kopein D, Katanaev VL. Drosophila GoLoco-protein pins is a target of Gal$\mathrm{pha}(\mathrm{o})$-mediated G protein-coupled receptor signaling. Mol Biol Cell 2009;20:3865-77.

[122] Cuppen E, van der Linden AM, Jansen G, Plasterk RH. Proteins interacting with caenorhabditis elegans galpha subunits. Comp Funct Genomics 2003;4:479-91.

[123] Willard FS, Kimple RJ, Siderovski DP. Return of the GDI: the GoLoco motif in cell division. Annu Rev Biochem 2004;73:925-51.

[124] Schaefer M, Shevchenko A, Shevchenko A, Knoblich JA. A protein complex containing Inscuteable and the Galpha-binding protein Pins orients asymmetric cell divisions in Drosophila. Curr Biol 2000;10:353-62.

[125] Gotta M, Ahringer J. Distinct roles for Galpha and Gbetagamma in regulating spindle position and orientation in Caenorhabditis elegans embryos. Nat Cell Biol 2001;3:297-300.

[126] Colombo K, Grill SW, Kimple RJ, Willard FS, Siderovski DP, Gonczy P. Translation of polarity cues into asymmetric spindle positioning in Caenorhabditis elegans embryos. Science 2003;300:1957-61.

[127] Hollinger S, Hepler JR. Cellular regulation of RGS proteins: modulators and integrators of G protein signaling. Pharmacol Rev 2002;54:527-59.

[128] Traver S, Bidot C, Spassky N, Baltauss T, De Tand MF, Thomas JL, et al. RGS14 is a novel Rap effector that preferentially regulates the GTPase activity of galphao. Biochem J 2000;350(Pt 1):19-29.

[129] Yi P, Johnson AN, Han Z, Wu J, Olson EN. Heterotrimeric G proteins regulate a noncanonical function of septate junction proteins to maintain cardiac integrity in Drosophila. Dev Cell 2008;15:704-13.

[130] Strittmatter SM, Valenzuela D, Kennedy TE, Neer EJ, Fishman MC. G0 is a major growth cone protein subject to regulation by GAP-43. Nature 1990;344:836-41.

[131] Nishimoto I, Okamoto T, Matsuura Y, Takahashi S, Murayama Y, Ogata E. Alzheimer amyloid protein precursor complexes with brain GTP-binding protein $G(0)$. Nature 1993;362:75-9.
[132] Offermanns S. G-proteins as transducers in transmembrane signalling. Prog Biophys Mol Biol 2003;83:101-30.

[133] Katanayeva N, Kopein D, Portmann R, Hess D, Katanaev VL. Competing activities of heterotrimeric G proteins in Drosophila wing maturation. PLoS ONE 2010;5:e12331.

[134] Sorkin A, von Zastrow M. Endocytosis and signalling: intertwining molecular networks. Nat Rev Mol Cell Biol 2009;10:609-22.

[135] Seto ES, Bellen HJ. Internalization is required for proper Wingless signaling in Drosophila melanogaster. J Cell Biol 2006;173:95-106.

[136] Blitzer JT, Nusse R. A critical role for endocytosis in Wnt signaling. BMC Cell Biol 2006;7:28.

[137] Doherty GJ, McMahon HT. Mechanisms of endocytosis. Annu Rev Biochem 2009; 78:857-902.

[138] Gagliardi M, Piddini E, Vincent JP. Endocytosis: a positive or a negative influence on Wnt signalling? Traffic 2008;9:1-9.

[139] Kikuchi A, Yamamoto H, Sato A. Selective activation mechanisms of Wnt signaling pathways. Trends Cell Biol 2009;19:119-29.

[140] Yu A, Rual JF, Tamai K, Harada Y, Vidal M, He X, et al. Association of Dishevelled with the clathrin AP-2 adaptor is required for Frizzled endocytosis and planar cell polarity signaling. Dev Cell 2007;12:129-41.

[141] Yamamoto $\mathrm{H}$, Komekado $\mathrm{H}$, Kikuchi A. Caveolin is necessary for Wnt-3adependent internalization of LRP6 and accumulation of beta-catenin. Dev Cell 2006;11:213-23.

[142] Zerial M, McBride H. Rab proteins as membrane organizers. Nat Rev Mol Cell Biol 2001:2:107-17.

[143] Seachrist JL, Laporte SA, Dale LB, Babwah AV, Caron MG, Anborgh PH, et al. Rab5 association with the angiotensin II type $1 \mathrm{~A}$ receptor promotes Rab5 GTP binding and vesicular fusion. J Biol Chem 2002;277:679-85.

[144] Esseltine JL, Dale LB, Ferguson SS. Rab GTPases bind at a common site within the angiotensin II type I receptor carboxyl-terminal tail: evidence that Rab4 regulates receptor phosphorylation, desensitization, and resensitization. Mol Pharmacol 2011;79:175-84.

[145] Hamelin E, Theriault C, Laroche G, Parent JL. The intracellular trafficking of the $G$ protein-coupled receptor TPbeta depends on a direct interaction with Rab11. J Biol Chem 2005;280:36195-205.

[146] Parent A, Hamelin E, Germain P, Parent JL. Rab11 regulates the recycling of the beta2-adrenergic receptor through a direct interaction. Biochem J 2009;418:163-72.

[147] Seabra MC, Wasmeier C. Controlling the location and activation of Rab GTPases. Curr Opin Cell Biol 2004;16:451-7.

[148] Boutros M, Mihaly J, Bouwmeester T, Mlodzik M. Signaling specificity by Frizzled receptors in Drosophila. Science 2000;288:1825-8.

[149] Strapps WR, Tomlinson A. Transducing properties of Drosophila Frizzled proteins. Development 2001;128:4829-35.

[150] Chen CM, Struhl G. Wingless transduction by the Frizzled and Frizzled2 proteins of Drosophila. Development 1999;126:5441-52.

[151] Bhanot P, Fish M, Jemison JA, Nusse R, Nathans J, Cadigan KM. Frizzled and Dfrizzled-2 function as redundant receptors for Wingless during Drosophila embryonic development. Development 1999.

[152] Cadigan KM, Fish MP, Rulifson EJ, Nusse R. Wingless repression of Drosophila frizzled 2 expression shapes the Wingless morphogen gradient in the wing. Cell 1998;93:767-77.

[153] Couso JP, Bishop SA, Martinez Arias A. The wingless signalling pathway and the patterning of the wing margin in Drosophila. Development 1994;120:621-36.

[154] Luo W, Lin SC. Axin: a master scaffold for multiple signaling pathways. Neurosignals 2004;13:99-113.

[155] Mao J, Wang J, Liu B, Pan W, Farr 3rd GH, Flynn C, et al. Low-density lipoprotein receptor-related protein-5 binds to Axin and regulates the canonical Wnt signaling pathway. Mol Cell 2001;7:801-9.

[156] Tamai K, Zeng X, Liu C, Zhang X, Harada Y, Chang Z, et al. A mechanism for Wnt coreceptor activation. Mol Cell 2004;13:149-56.

[157] Davidson G, Wu W, Shen J, Bilic J, Fenger U, Stannek P, et al. Casein kinase gamma couples Wnt receptor activation to cytoplasmic signal transduction. Nature 2005;438:867-72.

[158] Zeng X, Tamai K, Doble B, Li S, Huang H, Habas R, et al. A dual-kinase mechanism for Wnt co-receptor phosphorylation and activation. Nature 2005;438:873-7.

[159] Angers S, Thorpe CJ, Biechele TL, Goldenberg SJ, Zheng N, MacCoss MJ, et al. The KLHL12-Cullin-3 ubiquitin ligase negatively regulates the Wnt-betacatenin pathway by targeting Dishevelled for degradation. Nat Cell Biol 2006;8:348-57.

[160] Jung H, Kim HJ, Lee SK, Kim R, Kopachik W, Han JK, et al. Negative feedback regulation of Wnt signaling by Gbetagamma-mediated reduction of Dishevelled. Exp Mol Med 2009;41:695-706.

[161] Bryja V, Schulte G, Arenas E. Wnt-3a utilizes a novel low dose and rapid pathway that does not require casein kinase 1-mediated phosphorylation of Dvl to activate beta-catenin. Cell Signal 2007;19:610-6.

[162] Castellone MD, Teramoto H, Williams BO, Druey KM, Gutkind JS. Prostaglandin E2 promotes colon cancer cell growth through a Gs-axin-beta-catenin signaling axis. Science 2005;310:1504-10.

[163] Stemmle LN, Fields TA, Casey PJ. The regulator of G protein signaling domain of axin selectively interacts with Galpha12 but not Galpha13. Mol Pharmacol 2006;70:1461-8

[164] Day P, Kobilka B. PDZ-domain arrays for identifying components of GPCR signaling complexes. Trends Pharmacol Sci 2006;27:509-11. 
[165] Schwarz-Romond T, Merrifield C, Nichols BJ, Bienz M. The Wnt signalling effector Dishevelled forms dynamic protein assemblies rather than stable associations with cytoplasmic vesicles. J Cell Sci 2005;118:5269-77.

[166] Bilic J, Huang YL, Davidson G, Zimmermann T, Cruciat CM, Bienz M, et al. Wnt induces LRP6 signalosomes and promotes dishevelled-dependent LRP6 phosphorylation. Science 2007;316:1619-22.

[167] Schwarz-Romond T, Fiedler M, Shibata N, Butler PJ, Kikuchi A, Higuchi Y, et al. The DIX domain of Dishevelled confers Wnt signaling by dynamic polymerization. Nat Struct Mol Biol 2007;14:484-92.
[168] Yokoyama N, Golebiewska U, Wang HY, Malbon CC. Wnt-dependent assembly of supermolecular Dishevelled-3-based complexes. J Cell Sci 2010;123:3693-702.

[169] Sun Y, McGarrigle D, Huang XY. When a G protein-coupled receptor does not couple to a G protein. Mol Biosyst 2007;3:849-54.

[170] Verkaar F, Zaman GJ. New avenues to target Wnt/beta-catenin signaling. Drug Discov Today 2011;16:35-41. 